\title{
VARIABLE EFFECTS OF ANAESTHETICS ON THE VENTILATORY RESPONSE TO HYPOXAEMIA IN MAN
}

\author{
R.L. KNill and J.L. Clement
}

\begin{abstract}
We compared the ventilatory response to isocapnic hypoxaemia with a standard response to hyperoxic hypercarbia in human subjects sedated with methoxyflurane, diethyl ether or nitrous oxide, or anaesthetized with methoxyflurane. Compared to the awake state, methoxyflurane $0.1 \mathrm{MAC}$ sedation did not alter either response significantly; methoxyflurane 1.1 MAC anaesthesia depressed both, with a somewhat greater effect on the hypoxaemic response. Diethyl ether $0.1 \mathrm{MAC}$ sedation reduced only the hypoxaemic response. Nitrous oxide $0.1 \mathrm{MAC}$ reduced both hypoxaemic and carbon dioxide responses in parallel. The evidence suggests that all three agents - like thiopentone, halothane and enflurane - can impair the ventilatory response to isocapnic hypoxaemia in man, but that in relation to the carbon dioxide responses, the magnitude of this depressive effect varies. Halothane and enflurane are the most depressant, nitrous oxide and thiopentone the least, with methoxyflurane and diethyl ether appearing to be intermediate in effect.
\end{abstract}

Key WORDS: ANAesthetics, Vola tILE, diethyl ether, methoxyflurane; ANaEsTHETICS, GASES, nitrous oxide; HYPOXAEMIA, ventilatory response.

CONVENTIONAL WISDOM held that the ventilatory response to hypoxaemia was relatively rugged and resistant to depression by anaesthetics. 'This conclusion, based upon observations made in animals anaesthetized with barbiturates and/or narcotics, is not supported by recent studies in man. Thiopentone, halothane and enflurane anaesthesia clearly impair the ventilatory response to isocapnic hypoxaemia in $\operatorname{man},{ }^{2-4}$ with halothane and enflurane being particularly potent in this effect, depressing the hypoxic reflex out of proportion to their other ventilatory effects. These observations suggest that, rather than being resistant, the response to hypoxaemia may be relatively sensitive to depression by certain anaesthetics in man.

The purpose of the present study was to determine how three other anaesthetic agents methoxyflurane, diethyl ether and nitrous oxide

R.L. Knill, M.D., F.R.C.P.(C), Associate Professor and J.L. Clement, R.N., Department of Anaesthesia, University Hospital and University of Western Ontario, London. Canada.

This work was supported by the Medical Research Council of Canada.

Presented in part at a meeting of the Faculty of Anaesthetists, Royal Australasian College of Surgeons, Sydney, Australia, 1980.

Reprint requests to Dr. R.L. Knill, Department of Anaesthesia, University Hospital, P.O. Box 5339, Postal Stn. A., London, Canada. N6A 5 A5.

Can. Anaesth. Soc. J., vol. 29, no. 2, March 1982
- affect the ventilatory response to isocapnic hypoxaemia in human subjects.

\section{Methods}

The protocol for this study was approved by the Human Research Committee at the University of Westem Ontario.

We studied twenty fit subjects, fifteen during anaesthetic-induced sedation and five during full anaesthesia. Sedated subjects were anaesthetists, anaesthesia residents or respiratory technologists; anaesthetized subjects were in-hospital patients who had agreed to an extra period of anaesthesia before undergoing an elective orthopaedic surgical procedure. There were twelve males and eight females. Their ages, heights and weights were respectively $25 \pm 5$ years, $172 \pm$ $10 \mathrm{~cm}$ and $67 \pm 11 \mathrm{~kg}$ (means \pm S.D.)

Each subject was studied twice, first awake and then in one of four anaesthetic induced states - (1) sedation with methoxyflurane 0.1 MAC, (2) anaesthesia with methoxyflurane 1.l MAC, (3) sedation with diethyl ether $0.1 \mathrm{MAC}$, or (4) sedation with nitrous oxide 0.1 MAC.

For the awake portion of the study the subject sat in a comfortable chair in a darkened room and breathed through a mouthpiece with a nose-clip in place. He or she began by inhaling 100 per 
cent oxygen from a non-rebreathing system. When values of ventilation and end-tidal carbon dioxide had been steady for five minutes, we recorded resting ventilation for a one minute period.

Next, hypoxaemia was induced by the method of Weil, et al. ${ }^{5}$ Inhaled oxygen was gradually replaced with air and then with a mixture of air and nitrogen, so that end-tidal oxygen decreased to $5.3-6.0 \mathrm{kPa}(40-45$ torr) over an $8-10$ minute period. End-tidal carbon dioxide concentration was monitored continuously and carbon dioxide was added directly to inhaled gas if necessary to maintain end-tidal isocapnia.

Following a five minute rest, hypercarbia was induced by the rebreathing method of Read. ${ }^{6}$ The subject inhaled three large breaths from a closed circuit primed with carbon dioxide seven per cent in oxygen and then relaxed while continuing to rebreathe. If the tracing of the airway carbon dioxide concentration was steady throughout the respiratory cycle, rebreathing was permitted to proceed until the airway carbon dioxide concentration had increased $1.5-2.0$ per cent.

Sedation studies were conducted with subjects seated in the same room. To induce sedation, we administered methoxyflurane $0.04-0.08$ per cent for forty-five minutes $(n=5)$, diethyl ether $0.5-1.0$ per cent for forty-five minutes $(n=5)$; or nitrous oxide $10-15$ per cent for ten minutes $(n=5)$. In each case, the aim was to achieve and maintain a steady state of sedation with an end-tidal concentration of agent equivalent to 0.1 MAC. ${ }^{7}$ Tests and measurements were repeated as in the awake state except that anaesthetic agent was added to the test circuits to maintain sedation steady throughout testing periods.

Studies of methoxyflurane anaesthesia $(n=5)$ were conducted in a laboratory adjacent to the operating room complex. Each unpremedicated subject was positioned supine. Anaesthesia was induced with nitrous oxide 70 per cent and methoxyflurane with oxygen, supplemented by intravenous thiopentone $1-2 \mathrm{mg} \cdot \mathrm{kg}^{-1}$ during the excitement phase. With the achievement of surgical anaesthesia the trachea was sprayed with lidocaine 4 per cent and then intubated with an 8 or $9 \mathrm{~mm}$ cuffed orotracheal tube. Subsequently, nitrous oxide was discontinued and inhaled methoxyflurane was maintained to achieve an equilibrated and steady anaesthetic state with an end-tidal methoxyflurane concentration equivalent to $1.1 \mathrm{MAC}^{7}$ This state was deemed present when ventilation and end-tidal concentrations of methoxyflurane and carbon dioxide had been constant for ten minutes and nitrous oxide concentrations were less than 3.0 per cent. In each case this required sixty minutes or more of inhalation.

With anaesthesia continuing, responses to carbon dioxide and hypoxaemia were tested as above, except that the Read circuit was primed with eight per cent carbon dioxide and methoxyflurane, and equilibration with the circuit was achieved by three to five large positive pressure inflations of the lungs. During the measurement of resting ventilation, a sample of arterial blood was withdrawn for subsequent analysis of blood gas tensions. Three anaesthetized subjects were given an intravenous bolus of doxapram 0.4 $\mathrm{mg} \cdot \mathrm{kg}^{-1}$, as an additional test of ventilatory chemosensitivity. ${ }^{8}$

During all tests in all states, exhaled gases were sampled continuously close to the airway and analyzed for their gas and vapour concentrations. Oxygen, carbon dioxide and nitrous oxide were measured with a Perkin-Elmer \# 1100 mass spectrometer calibrated regularly with Canadian Liquid Air Specialty Gases. Carbon dioxide was detected in the instrument mode which minimizes interference with nitrous oxide. Methoxyflurane and diethyl ether were measured with a Beckman LB2 infra-red gas analyzer using a halothane pickup head which had been purged with carbon dioxide 7-8 per cent. Each vapour signal was calibrated with known vapour mixtures prepared by injection of precisely measured liquid volumes into a flask of known volume, temperature and pressure. Exhaled gas data were displayed on a time-based recorder from which end-tidal concentrations could be read. Values of dried end-tidal oxygen and carbon dioxide concentrations were converted to tensions, using the measured barometric pressure of each testing day.

We measured inspired ventilatory volumes with a calibrated pneumotachograph, applying correction factors for the density and viscosity of the various gases inhaled.* Values of resting ventilation were the averages of one minute recordings. Values of instantaneous ventilation, which were determined throughout chemical response tests, were each the average of at least

*These factors had been previously determined by measuring the pneumotachograph responses to a range of gas mixtures, including those which were given in this study. 
TABLE I

\begin{tabular}{|c|c|c|c|c|}
\hline & \multicolumn{2}{|c|}{$\begin{array}{l}\text { Methoxyflurane 0.1 MAC } \\
n=5\end{array}$} & \multicolumn{2}{|c|}{$\begin{array}{l}\text { Methoxyflurane } 1.1 \mathrm{MAC} \\
n=5\end{array}$} \\
\hline & Awake & Sedation & Awake & Anaesthesia \\
\hline Ventilation & & & & \\
\hline (L/min) & $\begin{array}{l}6.7 \pm 1.1 \\
52 \pm 0.2\end{array}$ & $\begin{array}{l}6.3 \pm 0.7 \\
51 \pm 0.2\end{array}$ & $\begin{array}{l}6.8 \pm 0.5 \\
4.9 \pm 0.1\end{array}$ & $\begin{array}{l}6.1 \pm 0.4 \\
5.5 \pm 0.3\end{array}$ \\
\hline $\mathrm{PET}_{\mathrm{CO}_{2}} \underset{\text { (torr) }}{(\mathrm{kPa})}$ & $\begin{array}{c}3.2 \pm 0.2 \\
39 \pm 1.2\end{array}$ & $\begin{array}{c}3.1 \pm 0.2 \\
38 \pm 1.3\end{array}$ & $\begin{aligned} 4.9 & =0.1 \\
37 & \pm 0.6\end{aligned}$ & $\begin{array}{r}5.5 \pm 0.3 \\
41 \pm 2.1\end{array}$ \\
\hline $\mathrm{Pa}_{\mathrm{CO}_{2}}(\mathrm{kPa})$ & 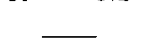 & (a) & - -20 & $6.1 \pm 0.3$ \\
\hline $\mathrm{CO}_{2}$ Response & & & & \\
\hline $\begin{array}{l}(\mathrm{L} / \mathrm{min} / \mathrm{kPa}) \\
(\mathrm{L} / \mathrm{min} / \mathrm{torr})\end{array}$ & $\begin{array}{r}14.9 \pm 2.5 \\
20 \pm 0.5\end{array}$ & $17.5 \pm 2.8$ & $11.3 \pm 2.2$ & $7.7 \pm 1.2 *$ \\
\hline $\begin{array}{l}\text { Hypoxaemic Response } \\
\Delta \dot{V} \mathbf{I}_{45} \\
(\mathrm{~L} / \mathrm{min})\end{array}$ & $\begin{array}{l}2.0 \pm 0.3 \\
7.3 \pm 1.8\end{array}$ & $\begin{array}{l}2.3 \pm 0.4 \\
5.2 \pm 1.3\end{array}$ & $\begin{array}{l}1.5 \pm 0.3 \\
6.2 \pm 1.4\end{array}$ & $\begin{array}{l}1.0 \pm 0.2 \\
1.8 \pm 0.6^{*}\end{array}$ \\
\hline
\end{tabular}

All values are MEANS \pm S.E.M.

*Significantly different from awake value $p<0.05$.

TABLE II

\begin{tabular}{|c|c|c|c|c|}
\hline & \multicolumn{2}{|c|}{$\begin{array}{l}\text { Diethyl Ether 0.1 MAC } \\
n=5\end{array}$} & \multicolumn{2}{|c|}{$\begin{array}{c}\mathrm{N}_{2} \mathrm{OO} 0.1 \mathrm{MAC} \\
\mathrm{n}=5\end{array}$} \\
\hline & Awake & Sedation & Awake & Sedation \\
\hline $\begin{array}{l}\text { Ventilation } \\
\text { (L/min) } \\
\mathrm{PET}_{\mathrm{CO}_{2}} \text { (kPa) } \\
\text { (torr) }\end{array}$ & $\begin{array}{r}5.9 \pm 0.3 \\
5.2 \pm 0.2 \\
39 \pm 1.3\end{array}$ & $\begin{array}{r}5.5 \pm 0.4 \\
5.2 \pm 0.2 \\
39 \pm 1.4\end{array}$ & $\begin{array}{r}6.5 \pm 1.1 \\
5.3 \pm 0.1 \\
40 \pm 1.1\end{array}$ & $\begin{array}{r}6.6 \pm 0.6 \\
5.3 \pm 0.1 \\
40 \pm 1.1\end{array}$ \\
\hline $\begin{array}{l}\mathrm{CO}_{2} \text { Response } \\
\text { (L/min/kPa) } \\
\text { (L/min/torr) } \\
\text { Hypoxaemic Response } \\
\Delta \dot{V}_{I_{45}} \\
(\mathrm{~L} / \mathrm{min})\end{array}$ & $\begin{array}{r}14.6 \pm 2.8 \\
1.9 \pm 0.4 \\
8.6 \pm 1.5\end{array}$ & $\begin{array}{c}14.8 \pm 2.6 \\
2.0 \pm 0.3 \\
5.9 \pm 1.5^{*}\end{array}$ & $\begin{array}{r}16.9 \pm 2.5 \\
2.3 \pm 0.3 \\
11.4 \pm 1.5\end{array}$ & $\begin{array}{l}9.2 \pm 1.3^{*} \\
1.2 \pm 0.2 \\
6.6 \pm 2.4^{*}\end{array}$ \\
\hline
\end{tabular}

All values are MEANS \pm S.E.M.

*Significantly different from awake value $p<0.05$

three consecutive breaths. All ventilatory volumes were expressed at B.T.P.S.

To depict the response to hypercarbia, we calculated the slope of the ventilation: $\mathrm{PCO}_{2}$ relationship using the method of least squares linear regression. The hypoxaemic response was represented by the " $\Delta \dot{V}_{\mathbf{I}_{45}}$ ", the measured increment in instantaneous ventilation from hyperoxia to a $\mathrm{PETCO}_{2}$ value of $6.0 \mathrm{kPa}$ (45 torr). The response to intravenous doxapram was represented by the maximum increment in instantaneous ventilation observed during the first sixty seconds following injection.

To assess possible differences between awake and sedation or anaesthetic states, we employed a two-tailed t-test for paired data, considering $\mathrm{p}$ values of 0.05 or less as indicative of a significant difference.

\section{RESULTS}

There were no complications of these studies, other than post-anaesthetic nausea and sore throat. Sedation with these agents did not alter arterial blood pressure or pulse rate significantly. Anaesthesia with methoxyflurane reduced systolic pressure modestly (average drop $2.3 \mathrm{kPa}$ from highest to lowest systolic values) and heart rate slightly (average decrease six beats/min).

Major ventilatory findings are summarized in Tables I and II and in Figures 1 and 2. Sedation did not significantly alter minute ventilation, tidal volume, breathing frequency or $\mathrm{PETCO}_{2}$. Anaesthesia with methoxyflurane did not reduce total minute ventilation significantly but reduced tidal volume from $524 \pm 89$ to $270 \pm 13 \mathrm{ml}$, increased breathing frequency from $13 \pm 1$ to 23 

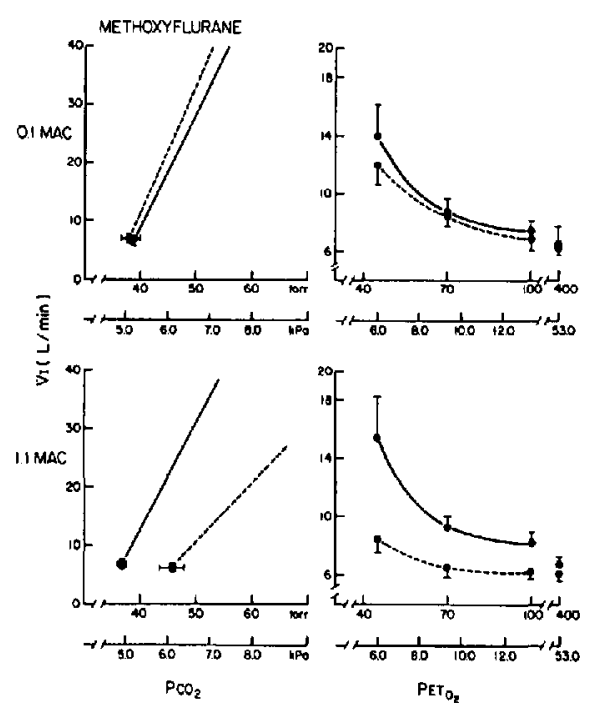

FIGURE 1 Ventilatory responses to hypercarbia (left) and to isocapnic hypoxaemia (right) during methoxyflurane 0.1 MAC sedation (upper) and methoxyflurane 1.1 MAC anaesthesia (lower). Carbon dioxide response slopes are shown as lines extending from points which depict resting ventilation and $\mathrm{PET}_{\mathrm{CO}_{2}}\left(\mathrm{~Pa}_{\mathrm{CO}}\right.$, during anaesthesia). Responses to hypoxaemia are lines hand drawn between points of ventilation observed at various PET $_{a_{2}}$ values. Points and lines represent mean values; bars depict standard errors of the means.
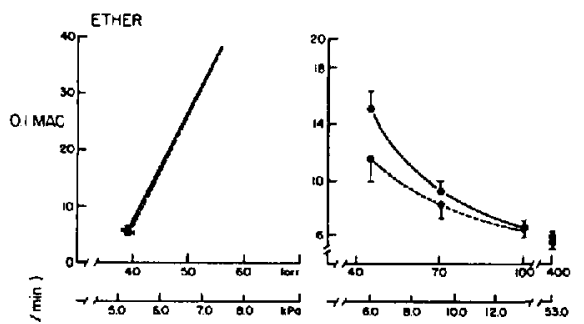

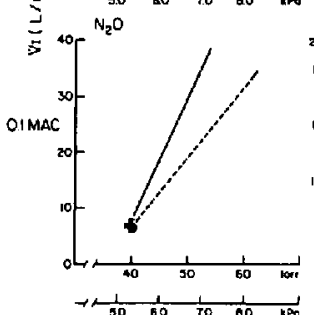

$\mathrm{PCO}_{2}$

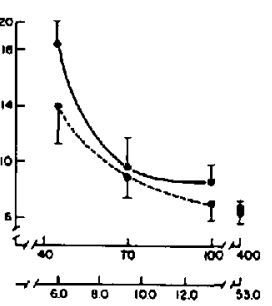

$\mathrm{PET}_{\mathrm{O}_{\mathrm{E}}}$
FIGURE 2 Ventilatory responses to hypercarbia (left) and to isocapnic hypoxaemia (right) during ether 0.1 MAC sedation (upper) and nitrous oxide 0.1 MAC sedation (lower). Format is similar to Figure 1. \pm 2 breaths/min (means \pm S.E.M., p values $<0.05$ ) and increased $\mathrm{PET}_{\mathrm{CO}_{2}}$ values slightly.

Methoxyflurane sedation did not significantly alter the ventilatory responses to hypercarbia and to hypoxaemia. Among individuals, methoxyflurane sedation had variable effects on responses to hypoxaemia. Whereas in three subjects sedation clearly reduced the hypoxaemic response, in two it had little or no effect. Methoxyflurane anaesthesia reduced the carbon dioxide response slightly and the hypoxaemic response considerably. Anaesthesia also decreased the response to intravenous doxapram $(15.9 \pm 2.3 \mathrm{l} / \mathrm{min}$ to $1.2 \pm 0.9 \mathrm{l} / \mathrm{min}$ ) (all $\mathrm{p}$ values $<0.05$ ). Diethyl ether sedation did not alter the carbon dioxide response but reduced the hypoxaemic response slightly $(\mathrm{p}<0.05)$. Nitrous oxide sedation caused modest and similar impairments of both responses ( $\mathrm{p}$ values $<0.05$ ). In all cases, the reduction of response to hypoxaemia was due primarily to a decrease in the tidal volume response with breathing frequency changes relatively unaffected

\section{Discussion}

The increment of ventilation in response to hypoxaemia in man is a reflex initiated by stimulation of peripheral chemoreceptors located in the carotid bodies. ${ }^{9}$ It has been known for many years that a variety of pharmacological agents have powerful depressive actions on these receptors and their associated reflexes, ${ }^{10,11}$ but this was not thought to be characteristic of intravenous and inhalational anaesthetics. ${ }^{1}$

Recently, Weiskopf, et $a l_{,}{ }^{12}$ and Hirshman, et $a l,{ }^{13}$ reported that barbiturates, ketamine, halothane, enflurane and isoflurane reduce the ventilatory response to hypoxaemia in dogs. Unfortunately the relevance of these observations to man was uncertain because of wellknown species differences, both quantitative and qualitative, in anaesthetic effects on breathing control, ${ }^{14,15}$ and in a number of pharmacological effects on peripheral chemoreflexes. ${ }^{10,16} \mathrm{Ac}$ cordingly we thought it necessary to undertake a series of studies to determine how anaesthetic agents influence the ventilatory response to hypoxaemia in man.

The design of the present study was similar to previous studies in the series. ${ }^{2-4}$ We evaluated the effects of methoxyflurane at both a sedating and an anaesthetizing dose, 0.1 and 1.1 MAC, but diethyl ether and nitrous oxide at the 0.1 MAC dose only. Studies of the ventilatory 
effects of a sedating dose alone might seem unlikely to be fruitful; however, previous observations made at a sedating dose of halothane and enflurane were in themselves sufficient to conclude that these agents had a potent and selective effect on the hypoxic response. ${ }^{3.4}$ With each agent and dose we compared changes in the activity of the hypoxic reflex to changes in the ventilatory response to added carbon dioxide, the latter being generally accepted as the most sensitive index of overall ventilatory control.

Experimental conditions were identical for awake and all three sedated states, but there were several variables added during anaesthesia - the supine position, tracheal intubation and the administration of thiopentone $1-2 \mathrm{mg} \mathrm{kg}^{-1}$ during induction. We believe that none of these variables influenced the outcome of the study in an important way. The supine position has no detectable effect on ventilatory responses to hypoxaemia and to carbon dioxide; ${ }^{17,18}$ tracheal intubation does not aiter chemoreflex activity during light halothane anaesthesia; ${ }^{4}$ and the ventilatory effects of a small dose of thiopentone given during halothane anaesthesia dissipate completely within thirty minutes. ${ }^{4}$

We tested the response to hypoxaemia using a modified Weil technique. ${ }^{5}$ Oxygen tension was lowered progressively over $8-10$ minutes, using end-tidal $\mathrm{PO}_{2}$ as the measured stimulus and keeping end-tidal carbon dioxide levels constant throughout. Although end-tidal $\mathrm{Po}_{2}$ is greater than arterial $\mathrm{PO}_{2}$ at arterial tensions below 10.0 $\mathrm{kPa}$ - where the ventilatory response is normally observed - this end-tidal to arterial difference is usually less than $0.8 \mathrm{kPa}$, in both awake ${ }^{5}$ and anaesthetized ${ }^{19}$ subjects. A raised carbon dioxide level augments the response to hypoxaemia, ${ }^{5}$ and during anaesthesia in this study $\mathrm{PCO}_{2}$ values were slightly increased (Table I). However, this $\mathrm{PCO}_{2}$ difference between awake and anaesthetized states would have acted only to underestimate the magnitude of the anaesthetic effect.

To measure the response to added carbon dioxide we employed the Read rebreathing technique. ${ }^{6}$ For studies of anaesthetics, this method is theoretically superior to steady-state techniques, because it maintains a constant relationship between measured and medullary carbon dioxide stimuli, independent of cerebral blood flow and cerebral metabolic rate - variables which are usually altered by anaesthesia.

All three agents studied reduced the ventilatory response to isocapnic hypoxaemia (Tables I and II, Figures 1 and 2). With methoxyflurane, depression was observed at the 1.1 MAC dose, with diethyl ether and nitrous oxide at the 0.1 MAC dose. Methoxyflurane and diethyl ether reduced the hypoxic response somewhat more than the carbon dioxide reponse; nitrous oxide impaired both proportionately. In addition, methoxyflurane anaesthesia reduced the ventilatory response to a dose of intravenous doxapram which stimulates only peripheral chemoreceptors. ${ }^{8}$ This effect was also relatively greater than the reduction of the response to carbon dioxide.

There are only limited human data with which our findings on the hypoxic response can be compared. That diethyl ether sedation reduced it selectively in our subjects is in agreement with the observation of Gordh that, during ether anaesthesia in man, the anoxic response is markedly depressed while the carbon dioxide response remains intact. ${ }^{20}$ Our finding that nitrous oxide was not particularly depressant, in relation to its effect on the carbon dioxide response, corroborates a clinical observation made often many years ago during anaesthesia with nitrous oxide alone. Hypoxic mixtures of nitrous oxide and oxygen, which were sometimes administered to achieve and/or maintain anaesthesia, were known to elicit a brisk hyperpnoeic response, and 100 per cent oxygen given in these circumstances to produce a temporary apnoea. ${ }^{21}$ These responses to low and high oxygen concentrations in the presence of nitrous oxide were clear evidence of an active hypoxic response. Somewhat inconsistent, however, are the data of Yacoub, et al., indicating that nitrous oxide $30-50$ per cent reduces the hypoxic response selectively and markedly. ${ }^{22}$ The explanation for these different observations is not clear, but may reside in the condition of Yacoub's subjects. In data depicted graphically in his report, values of resting ventilation appear very high, levels of $\mathrm{PCO}_{2}$ low and responses to carbon dioxide flat in the low $\mathrm{PCO}_{2}$ range - all indications that his subjects were not in a relaxed state, which is essential for reliable chemoreflex studies.

We have now examined the effects of six anaesthetic agents on the ventilatory response to isocapnic hypoxaemia and find that while all six can depress it, they do so with considerable variation in potency (Figure 3). Thiopentone and nitrous oxide reduce the response to hypoxaemia only in proportion to their reduction of the response to carbon dioxide. Halothane and enflurane, on the other hand, produce a marked 


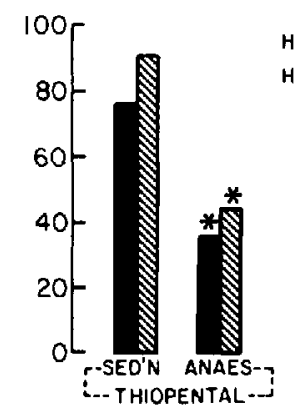

HYPERCARBIA

HYPOXAEMIA
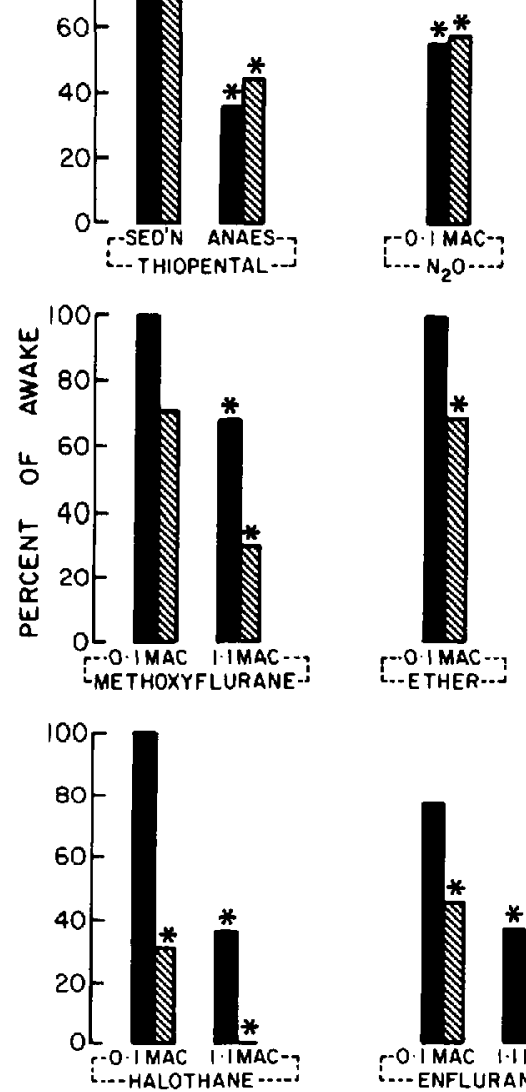

FIGURE 3 Effects of several anaesthetic agents on responses to hypercarbia and to hypoxaemia. Bar heights depict mean responses, expressed as percentages of awake values. Carbon dioxide responses were represented by slopes of $\dot{V}_{I}: \mathrm{PCO}_{2}$ relationships, and hypoxaemic responses by values of $\Delta \dot{V}_{\mathbf{L} 5}$. " indicates significant difference from awake. (Thiopentone, enflurane and halothane data are from references 2, 3 and 4.)

and selective depression, reducing the hypoxic reflex proportionately more than ventilation and the carbon dioxide response, at both sedating and anaesthetizing doses. Indeed, in about half the subjects anaesthetized with these agents, hypoxaemia causes ventilatory depression, the effect expected when peripheral chemoreflex activity is totally abolished. ${ }^{9}$ Methoxyfurane and diethyl ether appear to be intermediate in effect; they cause some selective depression, but clearly less than halothane and enflurane. Inter- estingly, these differences in responses to hypoxaemia were due primarily to differences in tidal volume responses, with frequency responses remaining more or less the same.

In the past we have speculated that the added depression of the hypoxic response over and above the reduction of the carbon dioxide response, as was observed with halothane and enflurane, is due to a vasodilating action of these agents on the local circulation of the carotid bodies. ${ }^{4 *}$ Since blood flow through the carotid bodies may respond to anaesthetics in a manner similar to the circulation of the brain (both derived from neural ectoderm), it was interesting to note that among the anaesthetic agents we tested there was a relationship between selective depression of the hypoxic reflex and known cerebral vasodilating properties. Those agents which selectively reduced hypoxic responsiveness (i.e. halothane, enflurane, methoxyflurane and diethyl ether) are those which increase cerebral blood flow, and those which did not (i.e. thiopentone and nitrous oxide) usually do not increase cerebral flow. ${ }^{23}$

The normal ventilatory response to hypoxaemia increases alveolar and arterial oxygen tension, and in doing so acts as an important physiological defence against hypoxaemia. It follows that patients anaesthetized with agents which reduce or abolish this response may be particularly vulnerable to the dangers of hypoxaemia. This vulnerability would be increased further if the same anaesthetic agents also impair other mechanisms that compensate for hypoxaemia, the most important among these being an increase in cardiac output. ${ }^{24}$ Although we have no direct information about the cardiac output response to hypoxaemia during anaesthesia in man, we have previously observed that halothane and enflurane in man impair the heart rate and systemic arterial pressure responses, ${ }^{25}$ effects which in other circumstances are linked closely to the cardiac output response. ${ }^{24}$

The clinician should be aware that during both anaesthesia and anaesthetic recovery, his patients may be severely compromised in their abilities to defend against hypoxaemia and to display the usual cardiorespiratory signs.

\section{ACKNOWLEDGEMENTS}

The authors wish to thank the subjects, the

*Indirect evidence suggests that vasodilation and the concomitant increase in local blood flow may reduce or eliminate hypoxic stimuli at tissue receptor sites. 
surgeons at University Hospital who cooperated in making the anaesthetic portion of the study possible, and Mrs. L. Nolan who assisted in preparing the manuscript.

\section{REFERENCES}

I. Comroe, J.H. The peripheral chemoreceptors. In Handbook of Physiology, Section 3: Respiration Volume I, Chapter 23, Washington, D.C. American Physiological Society (1964).

2. KNill, R.L., Bright, S. \& ManNinen, P.H. Hypoxic ventilatory responses during thiopentone sedation and anaesthesia in man. Can. Anaesth. Soc. J. 25(5): 366 (1978).

3. Knill, R.L., Manninen, P.H. \& Clement, J.L. Ventilation and chemoreflexes during enflurane sedation and anaesthesia in man. Can. Anaesth. Soc. J. 26(5): 353 (1979).

4. KNILL R.L. \& GELB, A.W Ventilatory responses to hypoxia and hypercapnia during halothane sedation and anesthesia in man. Anesthesiology 49: 244 (1978).

5. Weil, J.V., Byrne-Quinn, E., Sodal, I.E., FrIEsEN, W.O., UNDERHILl, B., Filley, G.F. \& Grover, R.F. Hypoxic ventilatory drive in normal man. J. Clin. Invest. 49: 1061 (1970).

6. READ, D.J.C. A clinical method for assessing the ventilatory response to $\mathrm{CO}_{2}$. Australas. Ann. Med. 16: 20 (1967)

7. Quasha, A.L., Eger, E.I. \& Tinker, J.H. Determination and applications of MAC. Anesthesiology 53: 315 (1980).

8. Severinghaus, J., Ozanne, G. \& Massuda, $Y$. Measurement of the ventilatory response to hypoxia. Chest $70: 121$ (1976).

9. WADE, J.G., LARSON, C.P. \& Hickey, R.F. Effect of carotid endarterectomy on carotid chemoreceptor and baroreceptor functions in man. N. Eng. J. Med. 282: 823 (1970).

10. Heymans, C. Action of drugs on carotid body and sinus. Pharmacol. Review 7:119 (1955).

11. Landgren, S., Liljestrand, G. \& ZotTerMAN, Y. The effect of certain autonomic drugs on the action potentials of the sinus nerve. Acta Physiol. Scand. 26: 264 (1952).

12. WeisKopf, R.B., Raymond, L.W. \& SeverINGHAUS, J.W. Effects of halothane on canine respiratory responses to hypoxia with and without hypercarbia. Anesthesiology 41: 350 (1974).

13. Hirshman, C.A., McCullough, R.E., COHEN, P.J., et al. Depression of hypoxic ventilatory response by halothane, enflurane and isoflurane in dogs. Br. J. Anaesth. 49: 957 (1977).

14. Gautier, H., Gaudy, J.H \& Bonora, M "Effects of anesthesia on breathing pattem." In Advances in Experimental Medicine \& Biology, Volume 99 . Edited by R.S. Fitzgerald, H. Gautier \& S. Lahiri. New York, Plenum Press, pp. 93 (1978).

15. Gautier, H. \& Gaudy, J.H. Changes in ventilatory pattern induced by intravenous anesthetic agents in human subjects. J. Appl. Physiol. 45: 171 (1978).

16. Black, A.H.S., Comroe, J.H. \& Jacobs, L. Species difference in carotid body response of cat and dog to dopamine and serotonin. Am. J. Physiol. 223: 1097 (1972).

17. RigG, J.R.A., RebuCK, A.S. \& CAMPBelL, E.J.M. The effect of posture on the ventilatory response to $\mathrm{CO}_{2}$, J. Appl. Physiol. 37: 487 (1974).

18. Slutsky, A.S., Goldstein, P.G. \& Rebuck, A.S. The effect of posture on the ventilator response to hypoxia. Can. Anaesth. Soc. J. 27: 445 (1980)

19. Kieraszemicz, H., Clement, J.L. \& Knill, R.L. Unpublished observations.

20. GORDH, T. Postural circulatory and respiratory changes during ether and intravenous anesthesia. Acta Chirurgica Scand. 62, suppl. 102: 25 (1945).

21. Clement, F.W. Nitrous oxide-oxygen anesthesia. Anesthesiology 7: 616 (1946)

22. Yacoub, O., Doell, D., KRYGer, M.H. \& ANTHONISEN, N.R. Depression of hypoxic ventilatory response by nitrous oxide. Anesthesiology $45: 385$ (1976).

23. Smith, A.L. \& Wollman, H. Cerebral blood flow and metabolism: Effects of anaesthetic drugs and techniques. Anesthesiology 36(4): 378 (1972).

24. KORNER, P.I. Circulatory adaptations in hypoxia. Physiological Reviews 39:687 (1959).

25. Manninen, P. \& KNILt, R.L. Cardiovascular signs of acute hypoxaemia and hypercarbia during enflurane and halothane anaesthesia in man. Can. Anaesth. Soc. J. 26: 282 (1979)

\section{RÉSUME}

Nous avons comparé la réponse ventilatoire provoquée par l'hypoxémie isocapnique avec une réponse standard à l'hypercarbie hyperoxique chez des humains sous sédation au méthoxyflurane, à l'éther diéthylique, au protoxyde d'azote et sous anesthésie au methoxyflurane. La sédation au methoxyflurane $0.1 \mathrm{MAC}$ n'a pas changé de façon significative aucune des deux réactions comparativement à l'état de veille; le methoxyflurane 1.1 MAC a déprimé les deux réponses. Le protoxyde d'azote 0.1 MAC a diminué la réponse à l'hypoxémie et à l'hypercarbie de façon parallèle. Ces résultats suggèrent que les trois agents étudiés comme le thiopentone, l'halothane et l'enflurane, peuvent modifier la réponse à l'hypoxémie isocapnique chez l'homme, mais que lorsqu'on étudie la réponse au gaz carbonique, l'importance de cet effet dépresseur est variable. L'halothane et l'enflurane sont les plus dépresseurs, le protoxyde d'azote et le thiopentone les moins dépresseurs, alors que le methoxyflurane et l'éther diethylique se situent entre les deux. 